\title{
Comparison of laparoscopic and traditional abomasal cannulation in sheep
}

\author{
Shixia Zhang, Manliang Hao, Yuzhong Ma \\ College of Veterinary Medicine, \\ Agricultural University of Hebei, Baoding 071000, China \\ shixiazhang2014@163.com
}

Received: October 25, 2015 Accepted: February 1, 2016

\begin{abstract}
Introduction: The objective of this study was to describe a laparoscopic abomasal cannulation (LAC) technique, and compare the extent of the surgical trauma after LAC and open abomasal cannulation (OAC) by examining postoperative visual analog scale (VAS) pain scores and serum values of interleukin-6 and tumour necrosis factor- $\alpha$ in sheep. Material and Methods: Twelve healthy ewes, weighing 38-43 kg, were used. Three-portal laparoscopic techniques were used for LAC procedures. OAC was performed by a right flank laparotomy. Results: Abomasal cannulation was accomplished in all sheep without major intraoperative and postoperative complications. The abomasal contents were collected easily in both groups. Comparative studies found that open procedures exhibit a more pronounced short-term increase in cytokines and significantly higher VAS pain scores than the corresponding laparoscopic procedures. Conclusion: The laparoscopic technique proved to be less traumatic than the conventional open technique.
\end{abstract}

Keywords: sheep, abomasal cannulation, laparoscopy, interleukin-6, tumour necrosis factor- $\alpha$.

\section{Introduction}

The cannulation of various regions of the digestive tract of ruminants is regarded as one of the most important procedures in nutritional studies $(1,15,16$, 18). Digestive tract fistulation was first used to study alimentary tract physiology in 1822. Cannulation of the abomasum has been used for abomasum examination (13) to obtain abomasal fluid (24), to measure abomasal emptying rate $(14,28)$, for parasitological (26) and pharmacological studies (5), and for the treatment of abomasal ulceration (23).

Many celiotomy techniques for abomasal cannulation have been described $(17,27)$, but these techniques are invasive, though to varying extents. Minimally-invasive laparoscopic surgery offers faster recovery times, reduced pain, and more rapid return to activity compared to conventional surgery (30). Therefore, laparoscopic surgery is becoming increasingly popular. Laparoscopic cryptorchidectomy (10), ovario-hysterectomy (8), gastropexy (29), and cystotomy for urolith removal have been reported (25).

Invasiveness is often measured by length of incision, severity of pain perceived, or recovery time.
These factors are difficult to measure in the animal environment (3). Acute-phase cytokines have been utilised to provide a more objective quantitative measure of operative trauma $(6,19)$. Thus, the object of the presented study was to describe a laparoscopic abomasal cannulation (LAC) technique and compare the inflammatory cytokine response after laparoscopic abomasal cannulation with traditional open abomasal cannulation (OAC).

\section{Material and Methods}

Animals. Twelve healthy ewes, 1 to 2 years of age and weighing 38 to $43 \mathrm{~kg}$, were used in the study. All sheep were assumed healthy based on physical examination and complete blood count (CBC). The housing and experimental facilities at the Agricultural University of Hebei were approved by the Chinese Ministry of Agriculture, and the study was approved by the Animal Ethics Committee of the Agricultural University of Hebei (Baoding, China). The sheep were divided into two equal groups: an LAC group and an OAC group. 
Surgical technique. Feed was withheld for $48 \mathrm{~h}$ and water for $12 \mathrm{~h}$ before operation. Ampicillin sodium (40 mg/kg, i.m.) was administered $1 \mathrm{~h}$ before surgery. Each sheep was premedicated with atropine $(0.05 \mathrm{mg} / \mathrm{kg}$ subcutaneously), and approximately $15 \mathrm{~min}$ later with ketamine (22 $\mathrm{mg} / \mathrm{kg}$, i.m.) and xylazine $(0.2 \mathrm{mg} / \mathrm{kg}$, i.m.). The ventral abdomen, from the paracostal area to the pubis and to each inguinal fold, was shaved, aseptically prepared, and draped for surgery.

Surgical procedures were performed by the same surgeon and two assistant surgeons.

LAC technique. Sheep were positioned in dorsal recumbency and the surgical table was tilted between $10^{\circ}$ and $20^{\circ}$ in a head-down position. The first trocarcannula $(10 / 11 \mathrm{~mm})$ unit for the laparoscope (Olympus, Germany) was placed on the midline, $2 \mathrm{~cm}$ caudal to the umbilicus. The second trocar-cannula $(10 / 11 \mathrm{~mm})$ unit was placed $12-16 \mathrm{~cm}$ lateral and $4-5 \mathrm{~cm}$ cranial to the left side of the umbilicus. The third trocar-cannula $(5-5.5 \mathrm{~mm})$ unit was placed $12-16 \mathrm{~cm}$ lateral and $2-3 \mathrm{~cm}$ caudal to the right side of the umbilicus. The $2^{\text {nd }}$ and $3^{\text {rd }}$ cannulas were used for placement of laparoscopic surgical instruments. Insufflations with $\mathrm{CO}_{2}$ were provided via automatic insufflators with pressure set 8 to $10 \mathrm{mmHg}$.

The serosal surface of the greater curvature of the abomasum was identified. Using forceps, the abomasum was grasped in the middle of its greater curvature (midway between the reticulo-abomasal ligament and the pyloric antrum), 2 to $3 \mathrm{~cm}$ from the attachment of the greater omentum. This site was the location of the cannula in the abomasum.

United States Pharmacopeia (USP) size 2-0 polyglycolic acid suture (swaged, round point $1 / 2$ circle needle, $30 \mathrm{~cm}, 5 \times 12$ ) was used for two traction sutures and one purse-string suture. The first traction suture was placed between the umbilicus and the xyphoid process, 3-5 cm lateral and 12-14 cm cranial to the right side of the umbilicus. Then a partial thickness purse-string suture ( $1 \mathrm{~cm}$ in diameter, 4-5 bites) was placed around the abomasal cannula site. The T-shape abomasal cannula pre-blocked with a sterilised tampon was fully inserted into the abdominal cavity. A stab incision a little smaller than the diameter of the T-shape abomasal cannula was then made into the abomasum lumen in the middle of the purse-string suture with a laparoscopic monopolar hook electrode. Then the abomasal cannula was inserted into the abomasum lumen through the stab incision and the purse-string suture tightened. The second traction suture was placed between the umbilicus and the xyphoid process, $3-5 \mathrm{~cm}$ lateral and 7-9 $\mathrm{cm}$ cranial to the right side of the umbilicus. A stab incision in the corresponding abdominal wall was created and the T-shape abomasal cannula was pulled through this incision out of the abdominal cavity with haemostatic forceps. Carbon dioxide was evacuated from the abdominal cavity by opening the cannulas and the $\mathrm{T}$-shape abomasal cannula was pulled against the body wall while the abomasum was approximated to the body wall by pulling on the traction sutures. The two traction sutures were tied and buried under the skin, which was closed with a cruciate suture pattern (2-0 polyglycolic acid) to create an abomasopexy. Lastly the T-shape abomasal cannula was secured to the skin with a fingertrap suture, and was clamped after removal of the sterilised tampon.

OAC technique. A right flank laparotomy, distal (approximately 2 to $3 \mathrm{~cm}$ ) and parallel to the last rib, was performed. The abomasum was identified and exteriorised. The location of the abomasal cannula was the same as for the laparoscopic group. A needle with polyglycolic acid suture was passed through the abdominal wall and then passed through the abomasal wall approximately $1 \mathrm{~cm}$ cranial to the abomasal cannula site without mucosal penetration. The needle was then pulled out of the abdominal cavity via the cutaneous incision to create the first traction suture. A partial thickness purse-string suture was placed around the abomasal cannula site. A stab incision with a diameter the same as for the laparoscopic group was made by scalpel. Then the abomasal cannula was inserted into the abomasum lumen through the stab incision. A stab incision in the corresponding abdominal wall was created; the location of the stab incision was the same as for the laparoscopic group. The T-shape abomasal cannula was pulled through this incision out of the abdominal cavity. The second traction suture was placed $1 \mathrm{~cm}$ caudal to the abomasal cannula site by use of the same technique and the same suture material as in the first traction suture. The location of the two traction sutures was the same as for the laparoscopic group. The two traction sutures were tied and buried under the skin which was closed with a cruciate suture pattern (2-0 polyglycolic acid) to create an abomasopexy. The T-shape abomasal cannula was secured to the skin by the same technique as for the laparoscopic group.

Postoperative care and monitoring. A systemic antibiotic (ampicillin sodium, $40 \mathrm{mg} / \mathrm{kg}$, i.m., every $8 \mathrm{~h}$ ) was administered for $5 \mathrm{~d}$ and flunixin meglumine $(0.5 \mathrm{mg} / \mathrm{kg}$, i.m., every $24 \mathrm{~h})$ was administered for $3 \mathrm{~d}$. Subjective assessment of the sheep's well-being and appetite, twice-daily measurements of temperature, and a daily complete blood count (CBC) were performed starting $7 \mathrm{~d}$ after surgery. Water was offered $6 \mathrm{~h}$ and feed $12 \mathrm{~h}$ after surgery.

Pain scores were registered using a visual analog scale (VAS) at $0 \mathrm{~h}, 6 \mathrm{~h}, 12 \mathrm{~h}, 1 \mathrm{~d}, 2 \mathrm{~d}$, and $3 \mathrm{~d}$ after surgery $(4,12)$. The VAS consists of a horizontal line, $10 \mathrm{~cm}$ in length, ranging from no pain (score 0 , the left end) to worst possible pain (score 10, the other end), and the observer assessed the pain by measuring the distance from the left end of the line to the mark.

Jugular vein blood samples were obtained prior to anaesthesia, immediately after the procedure, and on days 1, 3, 5, and 7 after surgery in both groups. Blood samples were collected in the early morning before feeding and allowed to clot at room temperature for about $30 \mathrm{~min}$. Then the blood was centrifuged for $10 \mathrm{~min}$ 
at $3000 \times \mathrm{g}$, and the obtained serum stored at $-80^{\circ} \mathrm{C}$ until analysis. The serum interleukin-6 (IL-6) and tumour necrosis factor- $\alpha$ (TNF- $\alpha$ ) levels were measured by ELISA using sheep ELISA kits (Uscn Life Science Inc, China), according to the manufacturer's protocols.

Statistical analysis. Standard statistical methods were used for the analysis of all results. Data are reported as mean \pm SD. Statistical differences within each group were determined by one-way ANOVA, and the paired-sample $t$ test was used to compare the two groups. The significance level was established as $\mathrm{P}<0.05$. Statistical analysis of data was performed with computer software (IBM, USA).

\section{Results}

All sheep recovered from the abomasal cannulation procedure without apparent surgical complications. LAC resulted in only two $10 \mathrm{~mm}$ and one $5 \mathrm{~mm}$ incisions in the body wall, for a total length of all incisions of $2.5 \mathrm{~cm}$. Mean surgical time, defined as time from the initial stab incision to closure of the last portal, was $49 \mathrm{~min}$ and actual times ranged from 42 to $58 \mathrm{~min}$. Mean surgical time of OAC was $22 \mathrm{~min}$ and actual times ranged from 18 to $26 \mathrm{~min}$. The abomasal contents were collected easily in both groups following clamp removal from the cannula barrel.

The sheep were administered additional pain medication after surgery. In the LAC group, VAS scores were the highest at $6 \mathrm{~h}$ after surgery (mean $\pm \mathrm{SD}$, $4.17 \pm 0.31$ ), most sheep were depressed and had a mild anorexia and abdominal pain, and resented palpation and examination of the operation sites. VAS scores decreased $1 \mathrm{~d}$ after surgery. Three days after surgery, the mean VAS score decreased to 1.58 (SD, 0.69), and all clinical symptoms returned to normal. In the traditional group, VAS scores were the highest $12 \mathrm{~h}$ after surgery (mean $\pm \mathrm{SD}, 4.25 \pm 0.42$ ), then decreased to 2.34 (SD, 0.45) $3 \mathrm{~d}$ after surgery. There were statistically significant differences in VAS pain scores between LAC and $\mathrm{OAC}$ at $6 \mathrm{~h}, 12 \mathrm{~h}$, and $1 \mathrm{~d}$ after surgery $(\mathrm{P}<0.05)$ (Fig. 1).

In both groups, the concentrations of serum inflammatory cytokine elevated immediately after surgery, but returned to normal at about $7 \mathrm{~d}$ after surgery. The concentration was higher in the OAC group than in the LAC group after surgery. The highest inflammatory cytokine concentration occurred at day 1 in both groups and was significantly higher in the OAC group than in the LAC group (Fig. 2).

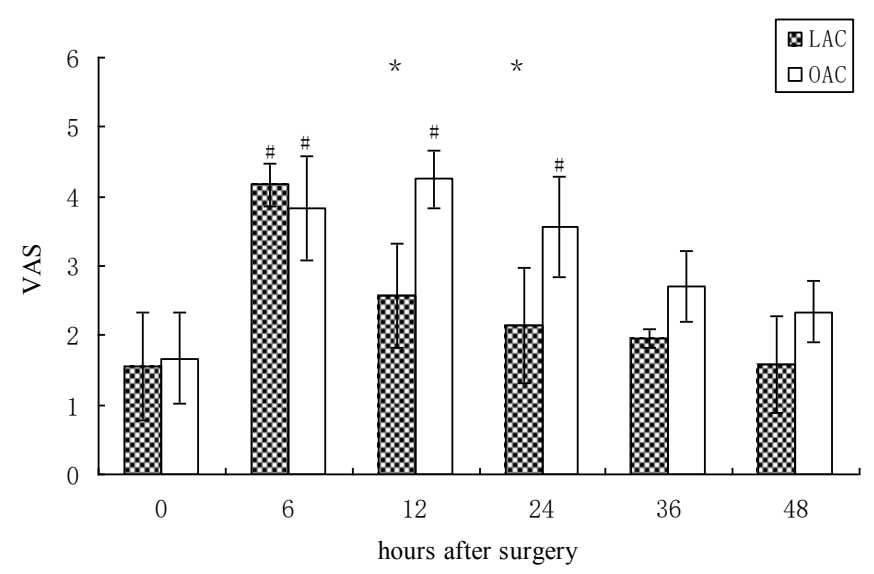

Fig. 1. Visual analog scale (VAS) pain scores after laparoscopic abomasal cannulation (LAC) and open abomasal cannulation (OAC). * $\mathrm{P}<0.05$ compared with $\mathrm{OAC}$; $\mathrm{P}<0.05$ compared with the baseline values
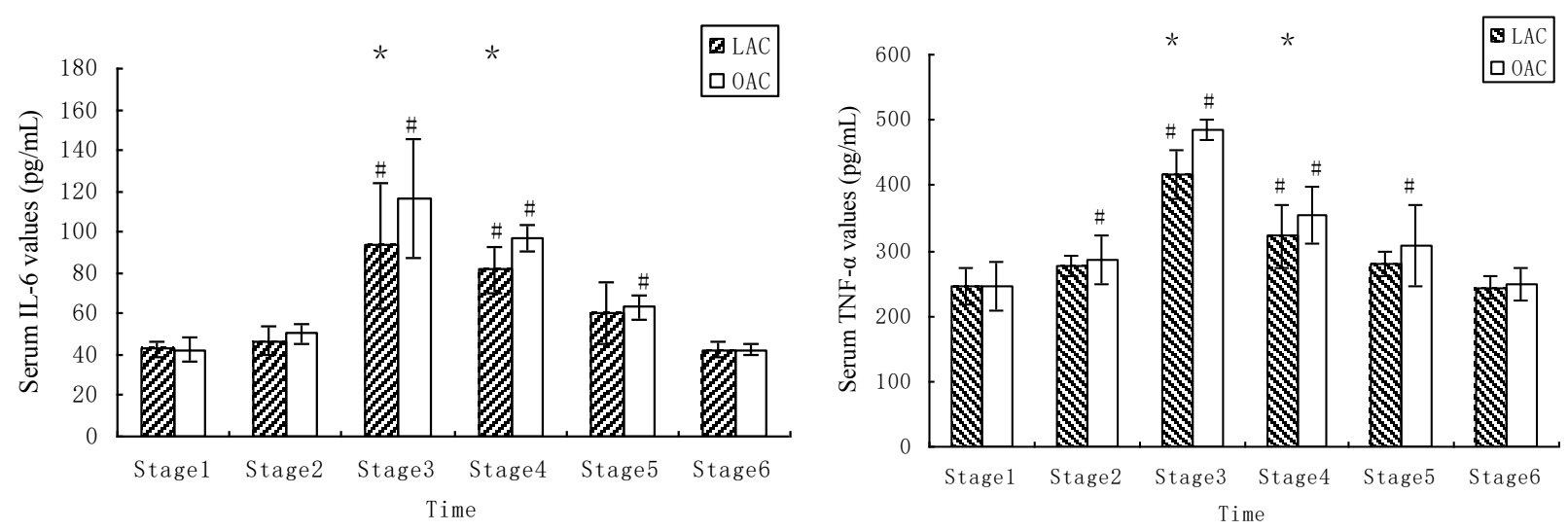

Fig. 2. Time course changes in IL-6 and TNF- $\alpha$ values for laparoscopic abomasal cannulation (LAC) and open abomasal cannulation (OAC). Stage 1 - before surgery; stage 2 - immediately after surgery; stage 3 - $1 \mathrm{~d}$ after surgery; stage 4 - $3 \mathrm{~d}$ after surgery; stage 5 - $5 \mathrm{~d}$ after surgery; and stage $6-7 \mathrm{~d}$ after surgery. ${ }^{*} \mathrm{P}<0.05$ compared with $\mathrm{OAC}$; \# $\mathrm{P}<0.05$ compared with the baseline values 


\section{Discussion}

LAC was performed in six healthy sheep, without major intraoperative or postoperative complications. The abomasal contents were collected each day after surgery to examine the usefulness of the $\mathrm{T}$-shaped abomasal cannula. Collection was easy in both groups following clamp removal from the cannula barrel. Thus LAC is an alternative technique to colopexy.

Data on the physiological impact of the laparoscopic abomasal cannulation approach are necessary. To compare the physiological impact of laparoscopic surgery with open surgery, postoperative serum cytokine levels were determined. Surgery induces a generalised state of immunodepression (19). Cytokines produced by cells of the immune system and other tissues act as mediators of the immune and acute phase response. TNF- $\alpha$, interleukin $1 \beta$ (IL-1 $1 \beta$ ), and IL-6 are the major mediators of the acute-phase response $(9,11)$. The postoperative levels of these cytokines have been found to correlate with the magnitude of the surgery and the presence of complications. They have, therefore, been accepted as markers of tissue trauma after surgery $(2,7)$. In the present study, the upregulation of inflammatory cytokines after laparoscopic abomasal cannulation and their return to baseline levels at 7 days indicate that tissue trauma associated with the overall surgical procedure was short-lived. The significant differences of the peak values of IL- 6 and TNF- $\alpha$, coupled with the statistically significant lower postoperative serum IL-6 and TNF- $\alpha$ levels in LAC compared with OAC, strongly supported the theory that laparoscopic technique is less traumatic than conventional open technique, as reported in literature $(21,22)$, and therefore LAC is a good alternative technique for abomasal cannulation in sheep.

Conflict of Interests Statement: The authors declare that they have no conflict of interests regarding the publication of this article.

Financial Disclosure Statement: This study was supported by the Scientific and Technological Research of Institution of Higher Learning Foundation of Hebei Province of China (Grant No. QN2015184).

Animal Rights Statement: The study was approved by the Animal Ethics Committee of the Agricultural University of Hebei (Baoding, China).

\section{References}

1. Allen A.J., Park K.T., Barrington G.M., Lahmers K.K., Abdellrazeq G.S., Rihan H.M., Sreevatsan S., Davies C., Hamilton M.J., Davis W.C.: Experimental infection of a bovine model with human isolates of Mycobacterium avium subsp. paratuberculosis. Vet Immunol Immunopathol 2011, 141, $258-266$.
2. Baigrie R.J., Lamont P.M., Kwiatkowski D., Dallman M.J., Morris P.J.: Systemic cytokine response after major surgery. Br J Surg 1992, 79, 757-760.

3. Bingener J., Krishnegowda N.K., Michalek J.E.: Immunologic parameters during NOTES compared with laparoscopy in a randomized blinded porcine trial. Surg Endosc 2009, 23, $178-181$.

4. Cambridge A.J., Tobias K.M., Newberry R.C., Sarkar D.K.: Subjective and objective measurements of postoperative pain in cats. J Am Vet Med Assoc 2000, 217, 685-690.

5. Charles B.G., Filippich L., Pass M.A.: Pharmacokinetics and absolute bioavailability of cyclosporine following intravenous and abomasal administration to sheep. J Pharm Pharmacol 1993, $45,821-824$

6. Choileain N.N., Redmond P.: Cell response to surgery. Arch Surg 2006, 141, 1132-1140.

7. Cruickshank A.M., Fraser W.D., Burns H.J., Van Damme J., Shenkin A.: Response of serum interleukin 6 in patients undergoing elective surgery of varying severity. Clin Sci 1990, 79, 161-165.

8. Davidson E.B., Moll H.D., Payton M.E.: Comparison of laparoscopic ovariohysterectomy and ovariohysterectomy in dogs. Vet Surg 2004, 33, 62-69.

9. Decker D., Lindemann C., Low A., Bidlingmaier F., Hirner A., von Ruecker A.: Changes in the cytokine concentration (IL-6, IL-8, IL-1ra) and their cellular expression of membrane molecules (CD25, CD30, HLA-DR) after surgical trauma. Zentralbl Chir 1997, 122, 157-163.

10. Dunay M.P., Németh T., Makra Z., Izing S., Bodó G.: Laparoscopic cryptorchidectomy and ovariectomy in standing horses using the EnSeal ${ }^{\circledR}$ tissue-sealing device. Acta Vet Hung 2012, 60, 41-53.

11. Dunker M.S., Ten Hove T., Bemelman W.A., Slors J.F., Gouma D.J., Van Deventer S.J.: Interleukin 6, C-reactive protein, and expression of human leukocyte antigen-DR on peripheral blood mononuclear cells in patients after laparoscopic vs. conventional bowel resection. Dis Colon Rectum 2003, 46, 1238-1244.

12. Firth A.M., Haldane S.L.: Development of a scale to evaluate postoperative pain in dogs. J Am Vet Med Assoc 1999, 214, 651-659.

13. Hertzberq H., Guscetti F., Bödeker D., Pospischil A., Eckert J.: Access to the abomasum of sheep via a rumen fistula for followup studies during trichostrongylid infections. Zentralbl Veterinarmed B 1994, 41, 237-248.

14. Holtenius K., Sternbauer K., Holtenius P.: The effect of the plasma glucose level on the abomasal function in dairy cows. J Anim Sci 2000, 78, 1930-1935.

15. Johnson R.R.: Techniques and procedures for in vitro and in vivo rumen studies. J Anim Sci 1966, 25, 855-875.

16. Knight J.S., Baird D.B., Hein W.R., Pernthaner A.: The gastrointestinal nematode Trichostrongylus colubriformis downregulates immune gene expression in migratory cells in afferent lymph. BMC Immunol 2010, 11, 51-62.

17. Komarek R.J.: Rumen and abomasal cannulation of sheep with specially designed cannulae and a cannula insertion instrument. J Anim Sci 1981, 53, 790-795.

18. Kristensen N.B., Engbaek M., Vestergaard M., Harmon D.L.: Technical note: ruminal cannulation technique in young Holstein calves: effects of cannulation on feed intake, body weight gain, and ruminal development at six weeks of age. J Dairy Sci 2010 , 93, 737-742.

19. Lennard T.W., Shenton B.K., Borzotta A., Donnelly P.K., White M., Gerrie L.M., Proud G., Taylor R.M.: The influence of surgical operations on components of the human immune system. Br J Surg 1985, 72, 771-776.

20. Leung K.L, Lai P.B., Ho R.L., Meng W.C., Yiu R.Y., Lee J.F., Lau W.Y.: Systemic cytokine response after laparoscopicassisted resection of rectosigmoid carcinoma: A prospective randomized trial. Ann Surg 2000, 231, 506-511. 
21. Mathon D.H., Dossin O., Palierne S., Cremoux M., Rodriguez H., Meynaud-Collard P., Steiner J.M., Suchodolski J.S., Lefebvre H.P., Autefage A.: A laparoscopic-sutured gastropexy technique in dogs: mechanical and functional evaluation. Vet Surg 2009, 38, 967-974.

22. Mathon D.H., Palierne S., Meynaud-Collard P., LayssolLamour C., Dulaurent-Ferrieres A., Colson A., Lacroix M., Bousquet-Melou A., Delverdier M., Autefage A.: Laparoscopicassisted colopexy and sterilization in male dogs: short-term results and physiologic consequences. Vet Surg 2011, 40, 500-508

23. Palmer J.E., Whitlock R.H.: Bleeding abomasal ulcers in adult dairy cows. J Am Vet Med Assoc 1983, 183, 448-451.

24. Pearson E.G., Guard C.L., Smith D.F.: A method for obtaining abomasal fluid via a rumen fistula. Cornell Vet 1981, 71, 183-187.

25. Rawlings C.: Endoscopic removal of urinary calculi. Compend Contin Educ Vet 2009, 31, 476-484.
26. Ross J.G., Purcell D.A., Todd J.R.: Experimental infection of calves with Trichostrongylus axei investigations using abomasal cannulae. Res Vet Sci 1969, 10, 46-56.

27. Rupp G.P., Kreikemeier K.K., Perino L.J., Ross G.S.: Measurement of volatile fatty acid disappearance and fluid flux across the abomasum of cattle, using an improved omasal cannulation. Am J Vet Res 1994, 55, 522-529.

28. Vlaminck K., van den Hende C., Oyaert W., Muylle E.: Studies on abomasal emptying in cattle. II. Effect of infusions in duodenum and abomasum on electromyographic complexes, pressure changes and emptying of the abomasum. Zentralbl Veterinarmed A 1984, 31, 676-682.

29. Wilson E.R., Henderson R.A., Montgomery R.D., Kincaid S.A., Wright J.C., Hanson R.R.: A comparison of laparoscopic and belt-loop gastropexy in dogs. Vet Surg 1996, 25, 221-227.

30. Zhang S.X., Wang H.B., Zhang J.T., Zhang N., Pan L.: Laparoscopic colopexy in dogs. J Vet Med Sci 2013, 75, 1161-1166. 